\title{
The relationship between the expression of serum IL-18 mRNA, CC16, and STREM-1 and the severity and prognosis of ventilator-associated pneumonia in elderly patients
}

\author{
Jing Wang ${ }^{1,2 \#}$, Ying Zhao ${ }^{1,2 \#}$, Li Pan ${ }^{1,2}$, Xuefeng $\mathrm{He}^{1,2}$, Xinglian Zhang ${ }^{1,2}$ \\ ${ }^{1}$ Gerontology ICU, Sichuan Provincial People's Hospital, University of Electronic Science and Technology of China, Chengdu, China; \\ ${ }^{2}$ ChineseAcademy of Sciences, Sichuan Translational Medicine Research Hospital, Chengdu, China \\ Contributions: (I) Conception and design: J Wang, Y Zhao, L Pan; (II) Administrative support: X He, X Zhang; (III) Provision of study materials or \\ patients: All authors; (IV) Collection and assembly of data: J Wang, Y Zhao, L Pan; (V) Data analysis and interpretation: J Wang, Y Zhao, L Pan; (VI) \\ Manuscript writing: All authors; (VII) Final approval of manuscript: All authors. \\ \#These authors contributed equally to this work. \\ Correspondence to: Xuefeng He. Gerontology ICU, 32 West Section 2, First Ring Road, Qingyang District, Chengdu 610072, China. Email: \\ hexuefeng188@163.com; Xinglian Zhang. Gerontology ICU, 32 West Section 2, First Ring Road, Qingyang District, Chengdu 610072, China. \\ Email: zhangxinglian0117@163.com.
}

Background This study aimed to explore the relationship between the severity and prognosis of elderly patients with ventilator-associated pneumonia (VAP) and the expression of serum interleukin-18 mRNA (IL18 mRNA), Clara cell secretory protein 16 (CC16) and the soluble triggering receptor expressed on myeloid cells 1 (sTREM-1).

Mothods: The patients were divided into a VAP group ( $\mathrm{n}=75)$ and a non-VAP group ( $\mathrm{n}=110)$. According to the Acute Physiology and Chronic Health Evaluation II (APACHEII) score, the patients with VAP were divided into a low-risk group, an intermediate-risk group and a high-risk group. According to the 28-day outcome, the patients were divided into a survival group and a death group. Serum levels of IL-18, CC16 and sTREM-1 were detected, and their value in the prediction and prognosis of VAP was analyzed using a receiver operating characteristic (ROC) curve.

Results: Serum levels of IL-18 and sTREM-1 in the VAP group were higher than those in the non-VAP group, while CC16 levels were lower in the VAP group than those in the non-VAP group $(\mathrm{P}<0.05)$. Serum levels of IL-18 and sTREM-1 decreased in order from the high-risk group to the intermediate-risk group to the low-risk group, while CC16 levels increased in order $(\mathrm{P}<0.05)$. ROC curve analysis showed that the Youden index and AUC of combined diagnosis of VAP with serum IL-18 mRNA, CC16 and sTREM-1 were 0.710 and 0.930 , which were higher than those of single diagnosis $(\mathrm{P}<0.05)$. Serum levels of IL-18 mRNA and sTREM-1 in the survival group were lower than those in the death group, and the CC16 level was higher than that in the death group $(\mathrm{P}<0.05)$. ROC curve analysis showed that the Youden index and AUC of combined diagnosis with serum IL-18 mRNA, CC16 and sTREM-1 were 0.506 and 0.731 , which were higher than those of single diagnosis $(\mathrm{P}<0.05)$.

Conclusions: The combination of these 3 factors is of high value in predicting the severity and prognosis of VAP and can provide reference for clinical treatment.

Keywords: Ventilator-associated pneumonia; interleukin-18 mRNA (IL-18 mRNA); Clara cell secretory protein
16 (CC16); soluble triggering receptor expressed on myeloid cells 1 (sTREM-1); prognosis

Submitted Nov 08, 2021. Accepted for publication Dec 15, 2021.

doi: 10.21037/apm-21-3511

View this article at: https://dx.doi.org/10.21037/apm-21-3511 


\section{Introduction}

Ventilator-associated pneumonia (VAP) is a pneumonia that occurs within 48 hours of extubation following mechanical ventilation (MV) (1). Due to the insufficient disinfection of the humidifier atomizer and other devices in the ventilator pipeline, the condensate in the ventilator pipeline is not poured in time, resulting in continuous inhalation of a large number of fog particles with high bacterial concentration, which is easy to cause VAP. And VAP can cause difficulties in ventilator weaning and, in severe cases, may result in the death of the patient. According to the domestic literature, VAP has a prevalence rate of $43.1 \%$ and a case fatality rate of $51.6 \%$ (2). Therefore, timely diagnosis and treatment are of the utmost importance. Studies have confirmed that inflammatory factors are involved in the pathogenesis and progression of VAP (3). Interleukin-18 (IL-18) is an important neutrophil chemotactic factor that can promote Th1 cytokine differentiation and Th2 cytokine secretion, produce immunoglobulin $\mathrm{E}(\mathrm{lgE})$ and immunoglobulin $\mathrm{G}(\mathrm{lgG})$ antibodies, and cause diseases such as immediate hypersensitivity and immune damage (4). Clara cell secretory protein 16 (CC16) is a functional protein secreted by Clara cells that plays a regulatory role in the inflammatory response (5). The soluble triggering receptor expressed on myeloid cells 1 (sTREM-1) belongs to the immunoglobulin superfamily and is often used to diagnose infectious diseases (6). When the body is infected, sTREM-1 can activate downstream signal transduction pathways, release inflammatory mediator factors, and expand the degree of the inflammatory response. At present, there are few studies on the relationship between IL-18, CC16, sTREM-1 and the severity and prognosis of elderly VAP patients, as well as the three-factor joint evaluation of prognosis. This study analyzed the expression of serum IL-18, CC16, and sTREM-1 in elderly VAP patients and explored their relationship with severity and prognosis. We present the following article in accordance with the STROBE reporting checklist (available at https://dx.doi. org/10.21037/apm-21-3511).

\section{Methods}

\section{General information}

A total of 185 patients who underwent ventilation therapy in the intensive care unit (ICU) of Sichuan Provincial People's Hospital from March 2019 to March 2021 were selected as the research subjects. The patients were divided into a VAP group ( $\mathrm{n}=75)$ and a non-VAP group $(\mathrm{n}=110)$. According to the Acute Physiology and Chronic Health Evaluation II (APACHEII) score, the VAP patients were divided into a low-risk group (0-10 points, $\mathrm{n}=25)$, an intermediaterisk group (10-20 points, $\mathrm{n}=30)$, and a high-risk group $(\geq 20$ points, $n=20$ ). These patients were further divided into a survival group $(\mathrm{n}=56)$ and a death group $(\mathrm{n}=19)$ according to the disease outcome within 28 days. The survival group consisted of 35 males and 21 females aged $(69.02 \pm 7.59)$ years, and the death group consisted of 12 males and 7 females aged $(68.68 \pm 7.51)$ years. There was no significant difference in general information between the 2 groups $(\mathrm{P}>0.05)$, which were therefore comparable. All procedures performed in this study involving human participants were in accordance with the Declaration of Helsinki (as revised in 2013). The study was approved by ethics committee of Sichuan Provincial People's Hospital [Lunshen (Research) No. 355-1, 2021] and informed consent was taken from all the patients.

\section{Inclusion and exclusion criteria}

The inclusion criteria were as follows: (I) all patients met the VAP diagnostic criteria (7) and underwent ventilation for $\geq 2$ days with $>2$ of the following criteria: (i) a body temperature of $>38^{\circ} \mathrm{C}$; (ii) wet rales detected by lung auscultation and purulent secretions in the respiratory tract; (iii) white blood cells $<4.0 \times 10^{9} / \mathrm{L}$ or $>10.0 \times 10^{9} / \mathrm{L}$; (iv) a chest $\mathrm{X}$-ray showed lung infiltration shadow; and (v) the respiratory tract secreted newly cultivated pathogenic bacteria. (II) The patients were between $60-80$ years old. (III) The patients provided informed consent. The exclusion criteria were as follows: (I) patients with severe liver and kidney dysfunction and lung diseases; (II) patients with malignant tumors; (III) patients with a bleeding tendency and severe arrhythmia; and (IV) patients with active hemoptysis and tuberculosis.

\section{Study method}

\section{Determination of serum IL-18 mRNA}

On the second day of admission, $5 \mathrm{~mL}$ of peripheral venous blood was taken, added to an ethylenediaminetetraacetic acid (EDTA) anticoagulation tube, diluted with phosphate buffer, and centrifuged at $2,000 \mathrm{r} / \mathrm{min}$ for 20 minutes. The cell concentration was adjusted to $5 \times 10^{5} / \mathrm{mL}$. The total RNA was extracted by the Trizol method. The upstream primer was 5'-ACCAGTAGAAGACAAT TGCATCAACT-3' and the downstream primer was 5'-CCAGGTTTTCATCATCTTCAGCTA-3'. The length 
Table 1 Comparison of clinical data between the VAP and non-VAP groups

\begin{tabular}{|c|c|c|c|c|c|c|c|c|c|}
\hline \multirow[b]{2}{*}{ Group } & \multirow[b]{2}{*}{ Men/women } & \multirow[b]{2}{*}{ Age } & \multirow[b]{2}{*}{$\operatorname{BMI}\left(\mathrm{kg} / \mathrm{m}^{2}\right)$} & \multicolumn{6}{|c|}{ Private string place, $\mathrm{n}(\%)$} \\
\hline & & & & Lung & Urinarytract & $\begin{array}{l}\text { Digestive } \\
\text { tract }\end{array}$ & Enterocoelia & $\begin{array}{c}\text { Central nervous } \\
\text { system }\end{array}$ & Blood \\
\hline $\begin{array}{l}\text { Non-VAP group } \\
(n=110)\end{array}$ & $58 / 52$ & $69.04 \pm 7.53$ & $24.50 \pm 2.18$ & $36(32.73)$ & $16(14.55)$ & $14(12.73)$ & $12(10.91)$ & $9(8.18)$ & $23(20.91)$ \\
\hline$P$ value & 0.794 & 0.490 & 0.559 & & & & 0.994 & & \\
\hline
\end{tabular}

VAP, ventilator-associated pneumonia; BMI, body mass index.

of the amplified fragment was $160 \mathrm{bp}$. The TaqMan probe was 5'-TGTGGCAATGAAATTTATTGACAATACG CTTTACTT-3'. The reverse transcription reaction was $3 \mu \mathrm{L}$ RNA template, $5 \times$ reverse transcription buffer $4 \mu \mathrm{L}$, upstream primer $(25 \mu \mathrm{mol} / \mathrm{L}) 0.4 \mu \mathrm{L}$, downstream primer $(25 \mu \mathrm{mol} / \mathrm{L}) 0.4 \mu \mathrm{L}$, deoxyribonucleotide triphosphate (dNTPs; $25 \mu \mathrm{mol} / \mathrm{L}$ ) $0.2 \mu \mathrm{L}$, Moloney murine leukemia virus (MMLV; $10 \mathrm{U} / \mu \mathrm{L}) 1 \mu \mathrm{L}$, and $11 \mu \mathrm{L}$ of diethyl pyrocarbonate (DEPC) water. The reaction conditions were $37^{\circ} \mathrm{C}$ for 1 hour and then $95^{\circ} \mathrm{C}$ for 3 minutes. The quantitative fluorescence polymerase chain reaction (PCR) system was $5 \times$ quantitative PCR buffer $10 \mu \mathrm{L}$, dNTPs $0.5 \mu \mathrm{L}$, Taq enzyme $1.5 \mu \mathrm{L}$, complementary DNA (cDNA) $5 \mu \mathrm{L}$, double-distilled water $\left(\mathrm{ddH}_{2} \mathrm{O}\right) 30 \mu \mathrm{L}$. The reaction conditions were $93{ }^{\circ} \mathrm{C}$ for 2 minutes and then $93{ }^{\circ} \mathrm{C}$ for 45 seconds, followed by $63{ }^{\circ} \mathrm{C}$ for 45 seconds, over 40 cycles.

\section{Determination of serum CC16 and sTREM-1 levels}

On the second day of admission, $5 \mathrm{~mL}$ of blood from the median cubital vein on an empty stomach was collected in the morning, stored in an EDTA anticoagulation tube, centrifuged at 3,000 r/min for 10 minutes, centrifuged to pellet the cells, and then stored in a constant temperature refrigerator at $-70{ }^{\circ} \mathrm{C}$. The serum CC16 and sTREM-1 levels were determined by enzyme-linked immunosorbent assay (ELISA). The model of the microplate reader was Bioelisa ELX-800 (BioTek, Winooski, VT, USA), and the kit was purchased from Nanjing Jiancheng Institute of Biological Engineering.

\section{Prognosis}

The patients were followed up for 28 days by telephone and outpatient services, and the survival conditions of the 2 groups were observed and recorded.

\section{Statistical methods}

The SPSS20.0 software (IBM corp., Armonk, NY, USA) was used to process the data, and the measurement data was indicated by $\left(\bar{x}_{ \pm s}\right)$. A one-way analysis of variance and a least significant distance (LSD) t test were performed, and the enumeration data were expressed by the rate (\%). A chi-squared test was performed. To evaluate the diagnostic value of serum IL-18 mRNA, CC16, and sTREM-1 levels for VAP severity and prognosis, a receiver operating curve (ROC) was drawn to obtain the area under the curve (AUC). An AUC $<0.5$ was of no value, 0.5 to 0.7 was of low diagnostic value, 0.7 to 0.9 was of moderate diagnostic value, and $>0.9$ was of high diagnostic value. A value of $\mathrm{P}<0.05$ indicated that the difference was statistically significant.

\section{Results}

Comparison of clinical data between the VAP and non-VAP groups

As shown in Table 1, there was no significant difference in gender, age, body mass index (BMI), APACHE II score, sequential organ failure assessment (SOFA) score, and disease location between the VAP group and the non-VAP group $(\mathrm{P}>0.05)$.

\section{Comparison of serum IL-18 mRNA, CC16, and sTREM-1 levels between the VAP and non-VAP groups}

As shown in Table 2, the levels of serum IL-18 mRNA and sTREM-1 in the VAP group were higher than those in the non-VAP group, and the levels of CC16 in the VAP group were lower than those in the non-VAP group $(\mathrm{P}<0.05)$. 
Table 2 Comparison of serum IL-18 mRNA, CC16, and sTREM-1 levels between the VAP and non-VAP groups $\left(\bar{x}_{ \pm s}\right)$

\begin{tabular}{lccc}
\hline Group & $\mathrm{IL}-18 \mathrm{mRNA}(\mathrm{copy} / \mathrm{\mu g})$ & $\mathrm{CC} 16(\mathrm{ng} / \mathrm{mL})$ & $\mathrm{sTREM}-1(\mathrm{pg} / \mathrm{mL})$ \\
\hline VAP group $(\mathrm{n}=75)$ & $257.11 \pm 31.93$ & $67.72 \pm 21.67$ & $152.58 \pm 22.96$ \\
Non-VAP group $(\mathrm{n}=110)$ & $218.44 \pm 18.15$ & $102.62 \pm 18.23$ & $128.01 \pm 8.08$ \\
$\mathrm{t}$ value & 19.166 & 3.200 & 75.532 \\
P value & $<0.001$ & $<0.001$ & $<0.001$ \\
\hline
\end{tabular}

IL-18, interleukin-18; CC16, Clara cell secretory protein 16; sTREM-1, soluble triggering receptor expressed on myeloid cells 1; VAP, ventilator-associated pneumonia.

Table 3 Comparison of serum IL-18 mRNA, CC16, and sTREM-1 levels in VAP patients with different disease levels $\left(\bar{x}_{ \pm s}\right)$

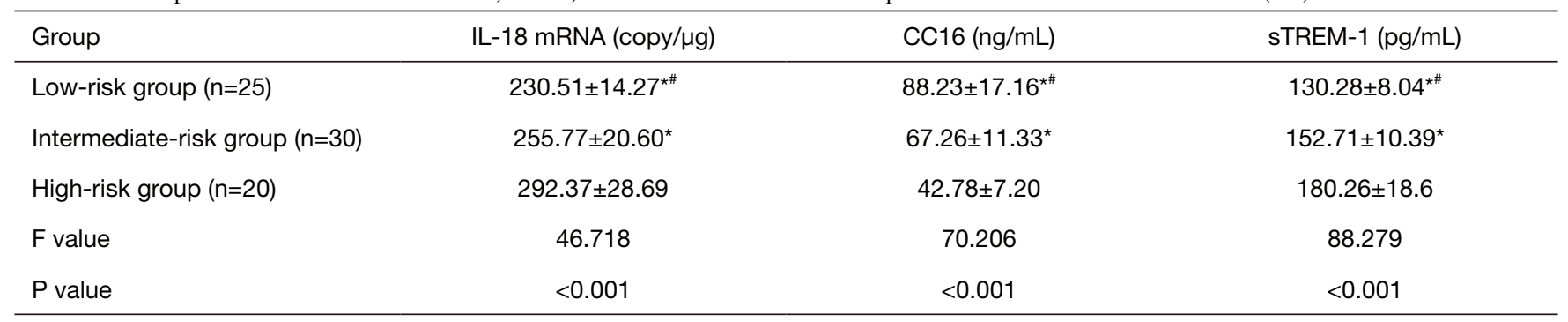

Compared with the high-risk group, ${ }^{*} \mathrm{P}<0.05$; compared with the middle-risk group, ${ }^{\#} \mathrm{P}<0.05$. IL-18, interleukin-18; CC16, Clara cell secretory protein 16; sTREM-1, soluble triggering receptor expressed on myeloid cells 1; VAP, ventilator-associated pneumonia.

Table 4 Serum IL-18 mRNA, CC16, and sTREM-1 levels effectively predict VAP

\begin{tabular}{lcccccc}
\hline Indicator & Sensitivity & Specificity & Youden index & AUC & $\begin{array}{c}\text { Asymptotically approaching, 95\% } \\
\text { confidence interval }\end{array}$ \\
\hline IL-18 mRNA & 0.627 & 0.955 & 0.581 & 0.875 & $0.802-0.911$ & $246.94 \mathrm{copy} / \mathrm{hg}$ \\
CC16 & 0.813 & 0.845 & 0.659 & 0.883 & $0.834-0.932$ & $85.615 \mathrm{ng} / \mathrm{mL}$ \\
sTREM-1 & 0.680 & 0.900 & 0.580 & 0.845 & $0.783-0.907$ & $138.76 \mathrm{pg} / \mathrm{mL}$ \\
Combine & 0.773 & 0.936 & 0.710 & 0.930 & $0.894-0.965$ & - \\
\hline
\end{tabular}

IL-18, interleukin-18; CC16, Clara cell secretory protein 16; sTREM-1, soluble triggering receptor expressed on myeloid cells 1; VAP, ventilator-associated pneumonia; AUC, area under the curve.

\section{Comparison of serum IL-18 mRNA, CC16, and sTREM-1 levels in VAP patients with different disease levels}

As shown in Table 3, the levels of serum IL-18 mRNA and sTREM-1 in the high-risk group were higher than those in the intermediate-risk group and the low-risk group, while the levels of CC16 in the high-risk group were lower than those in the intermediate-risk group and the low-risk group. The levels of serum IL-18 mRNA and sTREM-1 in the intermediate-risk group were higher than those in the low-risk group, while the levels of CC16 in the intermediate-risk group were lower than those in the low-risk group $(\mathrm{P}<0.05)$.

\section{Serum IL-18 mRNA, CC16, and sTREM-1 levels effectively predict VAP}

As shown in Table 4 and Figure 1, the ROC curve analysis showed that a diagnosis of VAP combined with serum IL-18 mRNA, CC16, and sTREM-1 levels had a Youden index of 0.773 , and $\mathrm{AUC}$ of 0.930 , which were higher than those diagnosed alone $(\mathrm{P}<0.05)$.

Comparison of serum IL-18 mRNA, CC16, and sTREM-1 levels in patients with different prognoses

As shown in Table 5, the levels of serum IL-18 mRNA and 
sTREM-1 in the survival group were lower than those in the death group, and the levels of CC16 in the survival group were higher than those in the death group $(\mathrm{P}<0.05)$.

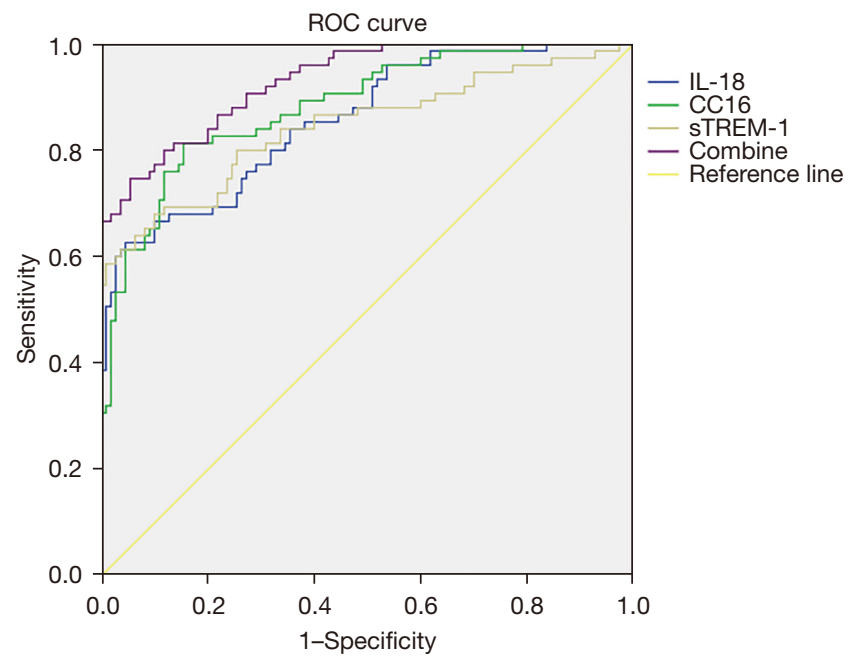

Figure 1 ROC curve analysis of serum IL-18 mRNA, CC16, and sTREM-1 levels in predicting VAP. ROC, receiver operating characteristic; IL-18 mRNA, interleukin-18 mRNA; CC16, Clara cell secretory protein 16; sTREM-1, soluble triggering receptor expressed on myeloid cells 1; VAP, ventilator-associated pneumonia.

\section{The efficacy of serum IL-18 mRNA, CC16, and sTREM-1 levels in predicting the prognosis of VAP}

As shown in Table 6 and Figure 2, the ROC curve analysis showed that the combined diagnosis of serum IL-18 mRNA, CC16, and sTREM-1 water had a Youden index of 0.506 and an AUC of 0.731 for the prognosis of VAP, which were higher than those of a single diagnosis $(\mathrm{P}<0.05)$.

\section{Discussion}

Epidemiological investigations show that the incidence of VAP in patients treated with MV in China is about 4.7$55.8 \%$, and the final mortality rate can reach $19.4-51.6 \%$ (8). VAP can lead to prolonged treatment time and induce drug-resistant strains. As VAP has no specific symptoms, it is difficult to diagnose and evaluate prognosis, and so identifying sensitive, reliable, simple, and rapid diagnostic indicators has become a current research hotspot (9).

IL-18 is a cytokine with a variety of immunomodulatory functions. It participates in airway inflammation and airway hyper responsiveness. It can promote $T$ helper type 1 (Th1) cell proliferation and immune response and induce $\mathrm{T}$ lymphocytes to secrete interferon and inflammatory cytokines $(10,11)$. Studies have shown that IL-18 is involved in the occurrence and development of bacterial pneumonia (12).

Table 5 Comparison of serum IL-18 mRNA, CC16 and sTREM-1 levels in patients with different prognoses $\left(\bar{x}_{ \pm \mathrm{s}}\right)$

\begin{tabular}{lccc}
\hline Group & $\mathrm{IL}-18 \mathrm{mRNA}(\mathrm{copy} / \mathrm{\mu g})$ & $\mathrm{CC} 16(\mathrm{ng} / \mathrm{mL})$ & $\mathrm{sTREM}-1(\mathrm{pg} / \mathrm{mL})$ \\
\hline Survival group $(\mathrm{n}=56)$ & $250.94 \pm 29.29$ & $71.31 \pm 20.57$ & $148.54 \pm 20.61$ \\
Death group $(\mathrm{n}=19)$ & $275.29 \pm 33.22$ & $57.14 \pm 21.88$ & $164.49 \pm 25.86$ \\
$t$ value & 0.267 & 0.023 & 1.957 \\
$\mathrm{P}$ value & $<0.001$ & $<0.001$ & $<0.001$ \\
\hline
\end{tabular}

IL-18, interleukin-18; CC16, Clara cell secretory protein 16; sTREM-1, soluble triggering receptor expressed on myeloid cells 1.

Table 6 The efficacy of serum IL-18 mRNA, CC16, and sTREM-1 levels in predicting the prognosis of VAP

\begin{tabular}{lcccccc}
\hline Indicator & Sensitivity & Specificity & Youden index & AUC & $\begin{array}{c}\text { Asymptotically approaching, 95\% } \\
\text { confidence interval }\end{array}$ \\
\hline IL-18 mRNA & 0.842 & 0.607 & 0.449 & 0.724 & $0.590-0.859$ & Cut-off value \\
CC16 & 0.737 & 0.768 & 0.505 & 0.714 & $0.564-0.865$ & $58.23 \mathrm{ng} / \mathrm{mL}$ \\
sTREM-1 & 0.579 & 0.875 & 0.454 & 0.702 & $0.546-0.858$ & $166.94 \mathrm{pg} / \mathrm{mL}$ \\
Combine & 0.684 & 0.821 & 0.506 & 0.731 & $0.588-0.874$ & - \\
\hline
\end{tabular}

IL-18, interleukin-18; CC16, Clara cell secretory protein 16; sTREM-1, soluble triggering receptor expressed on myeloid cells 1; VAP, ventilator-associated pneumonia; $\mathrm{AUC}$, area under the curve. 


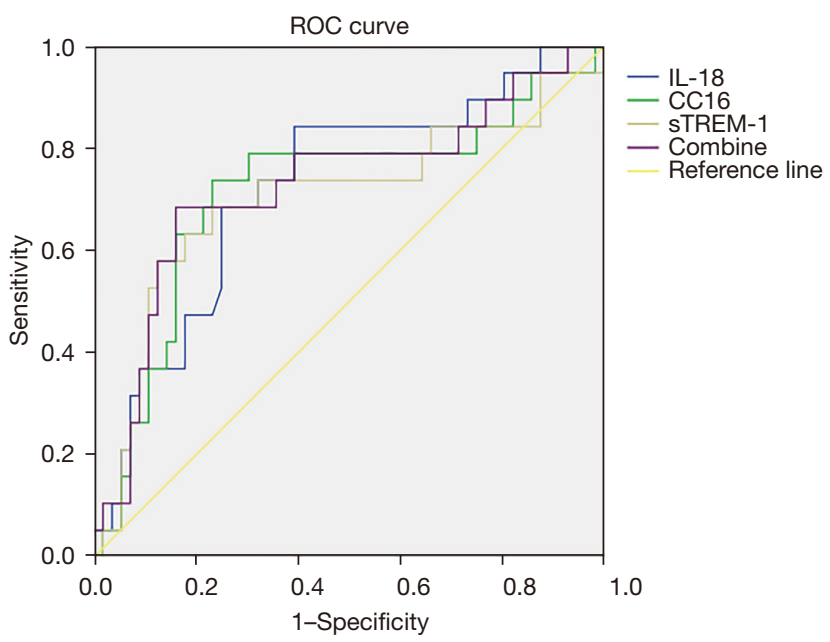

Figure 2 ROC curve analysis of serum IL-18 mRNA, CC16, and sTREM-1 levels in predicting the prognosis of VAP.ROC, receiver operating characteristic; IL-18 mRNA, interleukin-18 mRNA; CC16, Clara cell secretory protein 16; sTREM-1, soluble triggering receptor expressed on myeloid cells 1; VAP, ventilator-associated pneumonia.

Clara cells can repair damaged epithelial cells and secrete proteins and leukocyte protease inhibitors. CC16, the main protein secreted by Clara cells, participates in the regulation of immune function and inhibits inflammation $(13,14)$. Studies have confirmed that CC16 can be used as a marker for evaluating the integrity or permeability of lung epithelial cells (15). Determann et al. (16) have shown that CC16 can be used as a new biological indicator of pulmonary inflammation, which has important reference value for early prediction of VAP and severity. TREM-1, a member of the immunoglobulin family, can inhibit the expression of anti-inflammatory mediators, promote the release of proinflammatory mediators, and further activate and cascade to amplify the inflammatory response. The secretion subtype of TREM-1 is sTREM-1. sTREM-1 is released in the blood when the body is infected by bacteria, which protects the body from infection. In the initial infection stage, sTREM-1 can amplify the inflammatory response and promote the release of inflammatory factors. At the same time, the migration of inflammatory factor in the inflammatory part of the lung is closely related, which can reflect the severity of the infection in the body $(17,18)$. Zhao et al. have shown that sTREM-1 is a reliable predictor of VAP in neonates, and combined measurement of serum levels of sTREM-1 and PCT after $72 \mathrm{~h}$ of $\mathrm{MV}$ provided the most accurate prediction of VAP in neonatal patients (19).
The results of this study showed that the serum levels of IL-18 and sTREM-1 in the VAP group were higher than those in the non-VAP group, while the levels of CC16 in the VAP group were lower than those in the non-VAP group. This is consistent with the research conclusions of Zhao et al. (19), indicating that serum IL-18, CC16, and sTREM-1 levels are related to the occurrence of VAP. In addition, the present study found that serum IL-18 and sTREM-1 levels in the high-risk group were higher than those in the intermediate-risk group and the low-risk group, while CC16 levels in the high-risk group were lower than those in the intermediate-risk group and the low-risk group. The serum IL-18 mRNA and sTREM-1 levels in the intermediate-risk group were higher than those in the lowrisk group, while the CC16 levels in the intermediate-risk group were lower than those in the low-risk group. This suggests that serum IL-18 mRNA, CC16, and sTREM-1 levels can reflect the severity of VAP; as the disease becomes more severe, the expression levels of IL-18 and sTREM-1 rise and the expression levels of CC16 lower (20). The ROC curve analysis showed that the sensitivity of a diagnosis of VAP combined with serum IL-18, CC16, and sTREM-1 levels was $96.00 \%$. The AUC was 0.920 , which was higher than that of the diagnosis alone. This suggests that the combination of serum IL-18, CC16, and sTREM-1 levels can improve the diagnosis rate of VAP, and that clinical monitoring of these levels and targeted interventions should be carried out to reduce the incidence of VAP.

With regards to follow-up, our study found that serum IL-18 and sTREM-1 levels in the survival group were lower than those in the death group, while CC16 levels in the survival group were higher than those in the death group. This suggests that high levels of IL-18 and sTREM- 1 and low levels of CC16 can lead to poor prognosis. The ROC curve analysis showed that the combination of serum IL18, CC16, and sTREM-1 levels had a sensitivity of $92.00 \%$ for the prognosis of VAP. The AUC was 0.901, which was higher than that of the diagnosis alone. This suggests that the combined prognostic value of serum IL-18, CC16, and sTREM-1 levels in predicting the prognosis of VAP is relatively high, and that clinical monitoring of these levels and targeted interventions could improve the prognosis of patients. However, the number of cases included in this study was small, and further studies with larger sample sizes are required to confirm these results.

In summary, serum IL-18 and sTREM-1 levels in elderly VAP patients are highly expressed, while CC16 levels are low, and these levels are related to the severity of 
the disease. The combination of these 3 factors is of high value in predicting the severity and prognosis of VAP and is worthy of promotion and application in clinical treatment.

\section{Acknowledgments}

Funding: None.

\section{Footnote}

Reporting Checklist: The authors have completed the STROBE reporting checklist. Available at https://dx.doi. org/10.21037/apm-21-3511

Data Sharing Statement: Available at https://dx.doi. org/10.21037/apm-21-3511

Conflicts of Interest: All authors have completed the ICMJE uniform disclosure form (available at https://dx.doi. org/10.21037/apm-21-3511). The authors have no conflicts of interest to declare.

Ethical Statement: The authors are accountable for all aspects of the work in ensuring that questions related to the accuracy or integrity of any part of the work are appropriately investigated and resolved. All procedures performed in this study involving human participants were in accordance with the Declaration of Helsinki (as revised in 2013). The study was approved by ethics committee of Sichuan Provincial People's Hospital [Lunshen (Research) No. 355-1, 2021] and informed consent was taken from all the patients.

Open Access Statement: This is an Open Access article distributed in accordance with the Creative Commons Attribution-NonCommercial-NoDerivs 4.0 International License (CC BY-NC-ND 4.0), which permits the noncommercial replication and distribution of the article with the strict proviso that no changes or edits are made and the original work is properly cited (including links to both the formal publication through the relevant DOI and the license). See: https://creativecommons.org/licenses/by-nc-nd/4.0/.

\section{References}

1. Chacko R, Rajan A, Lionel P, et al. Oral decontamination techniques and ventilator-associated pneumonia. Br J Nurs 2017;26:594-9.
2. Razazi K, Arrestier R, Haudebourg AF, et al. Risks of ventilator-associated pneumonia and invasive pulmonary aspergillosis in patients with viral acute respiratory distress syndrome related or not to Coronavirus 19 disease.Crit Care2020;24:699.

3. Burja S, Belec T, Bizjak N, et al. Efficacy of a bundle approach in preventing the incidence of ventilator associated pneumonia (VAP). Bosn J Basic Med Sci 2018;18:105-9.

4. Jarret A, Jackson R, Duizer C, et al. Enteric Nervous System-Derived IL-18 Orchestrates Mucosal Barrier Immunity. Cell 2020;180:50-63.e12.

5. Vollrath JT, Stoermann P, Becker N, et al. Early local neutralization of CC16 in sepsis induced ALI following blunt chest trauma leads to delayed mortality without benefitting overall survival. Int J Mol Med 2020;46:2207-15.

6. Wright SW, Lovelace-Macon L, Hantrakun V, et al. sTREM-1 predicts mortality in hospitalized patients with infection in a tropical, middle-income country. BMC Med 2020;18:159.

7. Vijay G, Mandal A, Sankar J, et al. Ventilator Associated Pneumonia in Pediatric Intensive Care Unit: Incidence, Risk Factors and Etiological Agents. Indian J Pediatr 2018;85:861-6.

8. Osman S, Al Talhi YM, AlDabbagh M, et al. The incidence of ventilator-associated pneumonia (VAP) in a tertiarycare center: Comparison between pre- and post-VAP prevention bundle. J Infect Public Health 2020;13:552-7.

9. Ladbrook E, Khaw D, Bouchoucha S, et al. A systematic scoping review of the cost-impact of ventilator-associated pneumonia (VAP) intervention bundles in intensive care. Am J Infect Control 2021;49:928-36.

10. Bao J, Chen Z, Xu L, et al. Rapamycin protects chondrocytes against IL-18-induced apoptosis and ameliorates rat osteoarthritis. Aging (Albany NY) 2020;12:5152-67.

11. Miao N, Yin F, Xie H, et al. The cleavage of gasdermin D by caspase-11 promotes tubular epithelial cell pyroptosis and urinary IL-18 excretion in acute kidney injury. Kidney Int 2019;96:1105-20.

12. Gibellini L, De Biasi S, Paolini A, et al. Altered bioenergetics and mitochondrial dysfunction of monocytes in patients with COVID-19 pneumonia. EMBO Mol Med 2020;12:e13001.

13. Egron C, Labbé A, Rochette E, et al. Urinary club cell protein 16 (CC16): Utility of its assay during acute bronchiolitis. Pediatr Pulmonol 2020;55:490-5. 
14. Lam DC, Kwok HH, Yu WC, et al. CC16 levels correlate with cigarette smoke exposure in bronchial epithelial cells and with lung function decline in smokers. BMC Pulm Med 2018;18:47.

15. Johnson MDL, Younis US, Menghani SV, et al. CC16 binding to $\alpha 4 \beta 1$ integrin protects against mycoplasma pneumoniae infection. Am J Respir Crit Care Med 2021;203:1410-8.

16. Determann RM, Millo JL, Waddy S, et al. Plasma CC16 levels are associated with development of ALI/ ARDS in patients with ventilator-associated pneumonia: a retrospective observational study. BMC Pulm Med 2009;9:49.

17. Du C, Peng L, Kou G, et al. Assessment of Serum sTREM-1 as a Marker of Subclinical Inflammation in

Cite this article as: Wang J, Zhao Y, Pan L, He X, Zhang $\mathrm{X}$. The relationship between the expression of serum IL-18 mRNA, CC16, and sTREM-1 and the severity and prognosis of ventilator-associated pneumonia in elderly patients. Ann Palliat Med 2021;10(12):12767-12774. doi: 10.21037/apm-21-3511
Diarrhea-Predominant Patients with Irritable Bowel Syndrome. Dig Dis Sci 2018;63:1182-91.

18. Richard-Greenblatt M, Boillat-Blanco N, Zhong K, et al. Prognostic Accuracy of Soluble Triggering Receptor Expressed on Myeloid Cells (sTREM-1)-based Algorithms in Febrile Adults Presenting to Tanzanian Outpatient Clinics. Clin Infect Dis 2020;70:1304-12.

19. Zhao X, Xu L, Yang Z, et al. Significance of sTREM-1 in early prediction of ventilator-associated pneumonia in neonates: a single-center, prospective, observational study. BMC Infect Dis 2020;20:542.

20. Papazian L, Klompas M, Luyt CE. Ventilator-associated pneumonia in adults: a narrative review. Intensive Care Med 2020;46:888-906. 